\title{
Techno-Economic Analysis of Waste Heat Utilization in Data Centers: Application of Absorption Chiller Systems
}

\author{
Leyla Amiri ${ }^{1, *}$, Edris Madadian ${ }^{2}$, Navid Bahrani ${ }^{1}$ and Seyed Ali Ghoreishi-Madiseh ${ }^{3}$ \\ 1 Department of Civil and Resource Engineering, Dalhousie University, Sexton Campus, \\ Halifax, NS B3H 4R2, Canada; navid.bahrani@dal.ca \\ 2 Department of Chemical Engineering, University of Waterloo, Waterloo, ON N2L 3G1, Canada; \\ Edris.madadian@uwaterloo.ca \\ 3 Norman B. Keevil Institute of Mining Engineering, University of British Columbia, \\ Vancouver, BC V6T 1Z4, Canada; ali.madiseh@ubc.ca \\ * Correspondence: leyla.amiri@dal.ca
}

Citation: Amiri, L.; Madadian, E.; Bahrani, N.; Ghoreishi-Madiseh, S.A. Techno-Economic Analysis of Waste Heat Utilization in Data Centers: Application of Absorption Chiller Systems. Energies 2021, 14, 2433. https://doi.org/10.3390/en14092433

Academic Editors: Jan Danielewicz and Krzysztof Rajski

Received: 8 March 2021

Accepted: 22 April 2021

Published: 24 April 2021

Publisher's Note: MDPI stays neutral with regard to jurisdictional claims in published maps and institutional affiliations.

Copyright: (c) 2021 by the authors. Licensee MDPI, Basel, Switzerland. This article is an open access article distributed under the terms and conditions of the Creative Commons Attribution (CC BY) license (https:// creativecommons.org/licenses/by/ $4.0 /)$.

\begin{abstract}
Modern data centers are playing a pivotal role in the global economic situation. Unlike high-quality source of waste heat, it is challenging to recover the decentralized and low-quality waste heat sourced from data centers due to numerous technological and economic hurdles. As such, it is of the utmost importance to explore possible pathways to maximize the energy efficiency of the data centers and to utilize their heat recovery. Absorption chiller systems are a promising technology for the recovery of waste heat at ultra-low temperatures. In fact, the low temperature heat discharged from data centers cannot be retrieved with conventional heat recovery systems. Therefore, the present study investigated feasibility of waste heat recovery from data centers using an absorption chiller system, with the ultimate goal of electrical energy production. To fulfill this objective, a techno-economic assessment of heat recovery using absorption chiller (AC) technique for the data centers with power consumption range of 4.5 to $13.5 \mathrm{MW}$ is performed. The proposed AC system enables saving electricity for the value of 4,340,000 kWh/year and 13,025,000 kWh/year leading to an annual reduction of 3068 and 9208 tons $\mathrm{CO}_{2}$ equivalent of greenhouse gas (GHG) emissions, respectively. The results of this study suggest an optimum change in the design of the data center while reducing the payback period for the investors.
\end{abstract}

Keywords: waste heat recovery; absorption chiller; data center; sustainability; thermal pollution

\section{Introduction}

The incessant growth in the use of conventional fuels and their enormous greenhouse gas emissions necessitate more attention to be brought to environmental awareness. Consequently, many scholars around the world have been encouraged to spend significant amount of work on innovative technologies to supply heating and cooling demands of urban areas via renewable sources of energy. Global technological advancements and development of internet of things (IoT) technologies, big data, and cloud computing have resulted in rapid growth in the number of data centers around the world [1,2]. Owing to the enormous energy consumption resulted from rapidly growing data centers, much attention has been devoted to the possibility of energy recovery from such centers by their authorities as well as energy organizations. The worldwide electricity consumption of data centers is presented in four main categories: (i) Infrastructure uses $44.4 \%$ of electricity consumption (mainly ventilation and cooling sectors). (ii) Servers use $38.9 \%$ of energy supply, followed by $9.3 \%$ and $7.4 \%$ of the electricity used by (iii) Communication and (iv) Storage sectors, respectively [3-5].

Over 416 billion $\mathrm{kWh}$ of electricity was reportedly consumed by virtue of data processing in around 8 million data centers around the globe in 2019 [6]. A typical data center produces heat values in the range of 3.2 to $6.4 \mathrm{MW}$ comprising 250 sets of cabinets with 
42 to 64 server racks [7]. The new generations of data centers follow a growing trend of heat production with recent ones producing 10-250 $\mathrm{kW}$ [8]. In the light of the typical design temperature of $25^{\circ} \mathrm{C}$ for a data room, this makes data centers as a year-around stable source of heat, and there exists huge potential for waste heat recovery from data centers.

Waste heat recovery and utilization from data centers has been the subject of many research studies within the past decade leading to the introduction of several practices to recover low-grade waste heat. According to the literature, the waste heat can be categorized to four types based on temperature levels: high-grade, medium-grade, low-grade and ultra-low-grade waste heat in the temperature range of $>600{ }^{\circ} \mathrm{C}, 200-600^{\circ} \mathrm{C}, 80-200{ }^{\circ} \mathrm{C}$, and $45-80^{\circ} \mathrm{C}$, respectively $[9,10]$.

The most common practices include absorption cooling, district heating, and direct and/or indirect power generation [7,11,12]. Although several factors can affect selection of the best method, an overview of available techniques presents district heating as the most viable approach for waste heat recovery in data center. For example, ref. [13] investigated a hot water $\left(60^{\circ} \mathrm{C}\right)$ supercomputer prototype showing energetic and exergetic efficiencies of $80 \%$ and $34 \%$, respectively. Huang et al. [6] studied a $1 \mathrm{MW}$ data center showing over $97 \%$ of heat recovery, which is equivalent to the heat required of a $30,000 \mathrm{~m}^{2}$ commercial property. Another study investigated possible strategies for cooling and waste heat recovery of information technology (IT) servers in UK which produced over 2 million tons of $\mathrm{CO}_{2}$ [14] They projected that the recovered heat would be sufficient to supply heat demands for some neighborhoods in London. A 4000 ton $\mathrm{CO}_{2}$ equivalent emission reduction along with $\$ 170,000$ saving from waste heat recovery of a $3.5 \mathrm{MW}$ data center was estimated. A universal design approach was proposed by Fang et al. [15] for district heating based on the industrial waste heat recovery. They estimated that $122 \mathrm{MW}$ would suffice district heating of a city with a population of 4.6 million in Northern China resulting in reduction of 168,000 tons of $\mathrm{CO}_{2}$ equivalent. A steady-state model was developed in [16] which utilized the recovered heat from a thermosyphon-assisted air conditioner.

A variety of studies have been published exploring cooling technologies for thermal management in data centers [17-19]. A common practice to form hot and cold aisles in data centers is to place server racks back to back and front to front in an open-aisle (OA) air-cooled configuration [20]. This technique, however, affects the electricity consumption dedicated to air conditioning due to temperature nonuniformity sourced from air circulation between the cold and hot aisle [21]. Similar results was presented in [22], indicating potential weakness of OA systems associated with airflow direction. Alternatively, enclosed aisle (EA) approach was considered by numerous studies to reduce the inhomogeneity of airflow $[23,24]$. Nevertheless, EA strategy may also raise a new issue with finding the right place to discharge the trapped hot air. Consequently, other promising cooling systems such as free cooling, liquid cooling, two-phase technologies, and building envelope have been subject of many studies up until now. For instance, the authors of [25] modeled the dynamic air conditioning load of a large data center in China to obtain cooling and index. Using simulation of building load characteristics, it appeared that the values of annual cumulative heat load was much higher than its cooling one. A novel heat recovery system composed of data room, refrigeration unit, cooling tower, double conditions heat pump unit, auxiliary boiler, water pump, and pipeline valve refrigeration was proposed.

The low temperature of the waste heat sourced from data centers hinders producing a high-quality energy which requires a reliable technology to make up for this weakness. Among the waste heat recovery technologies reported in the literature, absorption chiller (AC) and Organic Rankine Cycle (ORC) were identified as the most promising technologies for processing waste heat from data centers. Both technologies have shown reliable performance in recovering low-grade source of heats.

The ORC technology has been considered as a valid solution for ultra-low-grade data center waste heat recovery. For instance, the authors of [26] investigated the technoeconomic performance of ORC as the means of waste heat recovery from data centers. Using a developed steady-state thermodynamic model, they examined the effect of different 
types of working fluid (i.e., dry, wet, and isentropic) and the evaporator temperature on the competence of the system. It was concluded that ORC would show the greatest performance in extremely low temperature applications. It was shown that the addition of superheaters in the server cooling cycle demands extra power for the operation which ultimately caused a performance drop, albeit at the higher temperature, the performance of ORC in waste heat recovery improves. A payback period of 4-8 years was estimated for the use of ORC in the data center. In a similar study, the authors of [27] built a $20 \mathrm{~kW}$ ORC prototype receiving the waste heat from two common rack servers operating at full capacity and with temperature ranging from $60{ }^{\circ} \mathrm{C}$ to $85^{\circ} \mathrm{C}$. The results of the experimental rig demonstrated thermal efficiency of $3.33 \%$ which was in a good agreement with the range of efficiency (i.e., $2 \%$ to $8 \%$ ) resulted from the thermodynamic model in the same study. The benefits of the ORC system were not limited to absorbing waste heat from the data center as it sent back the generated electricity to the data center. A recent study [28] investigated heat waste recovery from a simulated condition for a typical data center server rack using a lab-scale ORC. It was demonstrated that for the range of ultra-low waste heat (i.e., $45^{\circ} \mathrm{C}$ to $80{ }^{\circ} \mathrm{C}$ ), thermal efficiencies vary between $1.9 \%$ and $4.6 \%$. It was shown that significant fluid temperature differences in the heat exchanger, caused exergy deterioration to the ORC system.

AC systems, on the other hand, are not only able to handle low temperature source of heats, but also adopt waste heats from liquid-cooled and two-phase cooled data centers which further enhance their applicability in the field. The other advantages of AC systems are their low electricity cost, while their requirement for larger cooling tower is considered as their main drawbacks. AC systems mainly address some serious energy and environment issues with the conventional compression chiller (CC) systems. Despite recent achievements in recovering waste heat from data centers, yet underlying concept needs to be further explored broadly. Therefore, the present research investigates feasibility of energy recovery from the heat dissipated by a number of servers to support an AC unit which can further supply cooling requirements for other centers.

\section{Methodology}

With the purpose of perform the techno-economic study, an inventory of information from a variety of AC manufacturers in the North America were established allowing to analyze utilization and performance of various types of AC systems which are now ready for use for many purposes. Trane and Yazaki [29,30] were selected as AC manufacturing pioneers in the North America. The main reason for the selection of the two manufacturers is their diversity in ultimate application of heat recovered from data centers. Trane develops AC systems working under the low-grade hot water in a range of $70{ }^{\circ} \mathrm{C}$ and $110{ }^{\circ} \mathrm{C}$ which makes them promising options to recover waste heat in in data centers [29]. Yazaki operates AC units using water-lithium-bromide as the refrigerant which is capable to operate with low quality waste heat (temperature: $70-95^{\circ} \mathrm{C}$ ) [30]. The Yazaki AC units will shut down if the inlet hot water temperature exceeds $95^{\circ} \mathrm{C}$. The outlet hot water temperature is $\sim 55^{\circ} \mathrm{C}$. It should be mentioned that the low-grade heat generated through industrial processes can be used by AC systems and generates cooling energy. Otherwise, this low-grade heat will be wasted and discarded through the environment. The other important point about the AC systems is their sensitivity to the temperature of the inlet hot water as an energy source. If the temperature of the inlet hot water is less than the desired temperature, the efficiency and the cooling capacity of the system is reduced as well.

This work provides a substantive methodological guide for district heating using the recovered heat from data centers. Thus, the main idea of this study is to employ an AC unit which is energized by the low-grade heated air in the data centers (Figure 1). When the enough heat load is supplied to AC system, the heat load on the CC unit is reduced. In the other words, a portion of the heated air in the data center will be removed by the AC, which reduces the total workload on the CC. Here, the heated air in the data center has a lower-grade heat compared to the higher-grade heat of the computing elements inside 
the racks. This low-grade heat air can be effectively cooled down by the AC. Finally, any remaining heat can be removed by the CC.

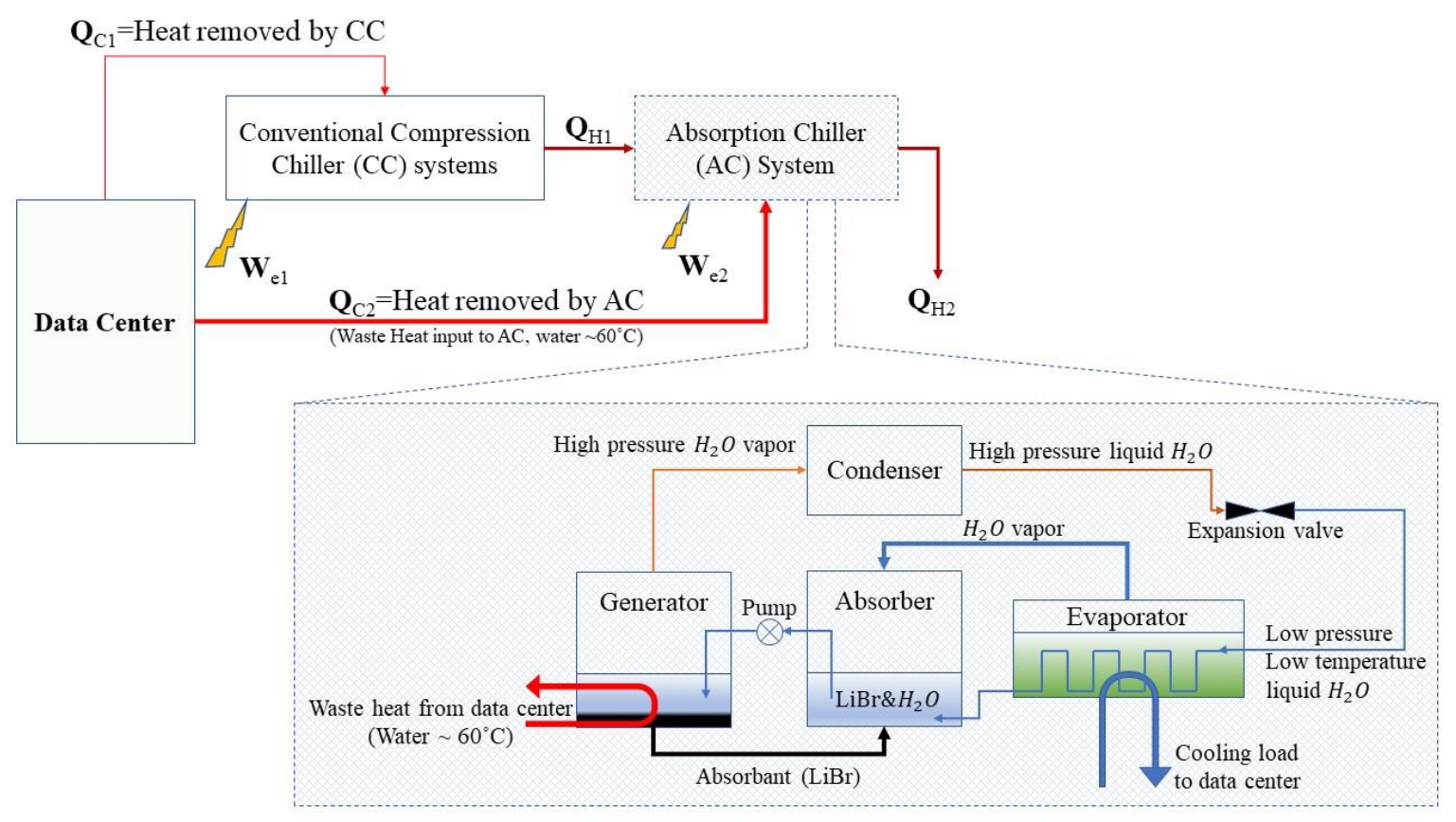

Figure 1. Heat flow of the proposed data center coupled with an absorption chiller system.

\section{Analytical Model}

The first step in developing the thermodynamic model for the proposed system is to apply governing equations predominantly conservation of mass and energy. The analytical model is implemented considering CC system as the point of comparison with the proposed AC system. Figure 1 presents the cycle under investigation for the heat flow of the proposed data center. Note that $Q_{H 1}$ is the heat rejected from the cycle through the condenser in the $\mathrm{CC}$ and can be proportionally considered as a heat source for the AC system. In addition, wet or dry cooling towers should be designed to transfer $Q_{H 2}$ (i.e., the heat rejected of the chiller coolant water by absorber and condenser) to the ambient.

According to Figure 1, the total cooling supplied by the hybrid CC system and AC system $\left(Q_{C-\text { total }}\right)$ can be written as (Equation (1))

$$
Q_{C-\text { total }}=Q_{C 1}+Q_{C 2}
$$

where $Q_{C 1}$ and $Q_{C 2}$ are the provided cooling by the CC system and AC system, respectively.

Similarly, total electricity consumption by the proposed hybrid CC-AC system $\left(W_{C C-A C}\right)$ can be written as follows (Equation (2)):

$$
W_{C C-A C}=W_{e 1}+\underbrace{W_{e 2}}_{\approx z e r o}
$$

where $W_{e 1}$ and $W_{e 2}$ are the electricity requirement for operating the CC system and $\mathrm{AC}$ system, respectively. Note that the energy consumption of the AC system in this integrated proposed system is negligible.

The provided cooling by the CC system $\left(Q_{C 1}\right)$ is a function of the Coefficient of Performance (COP) of the system as well as the dissipated heat $\left(Q_{H 1}\right)$ from the system and can be written as follows (Equations (3) and (4)):

$$
Q_{C 1}=C_{C O P} \times W_{e 1}
$$




$$
Q_{\mathrm{C} 1}=\frac{C O P_{\mathrm{CC}}}{1+\operatorname{COP}_{\mathrm{CC}}} \times Q_{H 1}
$$

According to the first and second law of thermodynamics, the dissipated heat and cooling by the CC system can be expressed as (Equations (5) and (6)):

$$
\begin{gathered}
Q_{H 1}=Q_{C 1}+W_{e 1}=\left(1+C O P_{C C}\right) \times W_{e 1} \\
Q_{C 2}=C O P_{A C} \times Q_{H 1}=C O P_{A C} \times\left(1+C O P_{C C}\right) \times W_{e 1}
\end{gathered}
$$

Combining Equations (3) and (5), the total cooling provided for the data center and the total electricity consumption by the proposed hybrid system can be rewritten as (Equation (7))

$$
Q_{C-\text { total }}=Q_{C 1}+Q_{C 2}=C O P_{C C} \times W_{e 1}+C O P_{A C} \times\left(1+C O P_{C C}\right) \times W_{e 1}
$$

The total electricity consumption by the proposed hybrid CC-AC system can be calculated using Equation (8):

$$
W_{C C-A C}=\frac{Q_{C-t o t a l}}{C O P_{C C}+C O P_{A C} \times\left(1+C O P_{C C}\right)}
$$

The total electricity saving of using the proposed system can be calculated using Equations (9) and (10):

$$
W_{\text {saving }}=W_{C C}-W_{C C-A C}
$$

Electricity saving $(\%)=\frac{W_{C C}-W_{C C-A C}}{W_{C C}}=1-\frac{C O P_{C C}}{C O P_{C C}+C O P_{A C} \times\left(1+C O P_{C C}\right)} \times 100$

A detailed economic analysis including both efficiency and performance for AC systems is carried out for a data center with a power consumption range of 4.5 to $13.5 \mathrm{MW}$.

In designing cooling system for modern data centers, the waste heat dissipated per rack could be assumed between 10 and $15 \mathrm{~kW}$. Note that if the rack is occupied with supercomputers, the heat generation can be up to $60 \mathrm{~kW}$ from each rack [31]. Accordingly, in the calculations, it is assumed that maximum $15 \mathrm{~kW}$ of waste heat is dissipated by each server rack (Figure 2). Additionally, water is used as cooling agent with the flowrate of 0.3 to $0.61 / \mathrm{s}$. The design temperature of outcoming water is assumed $70{ }^{\circ} \mathrm{C}$ which is somewhat lower than the typical temperature of $85^{\circ} \mathrm{C}$. This is ascribed to the heat loss of the intermediate heat exchanger.

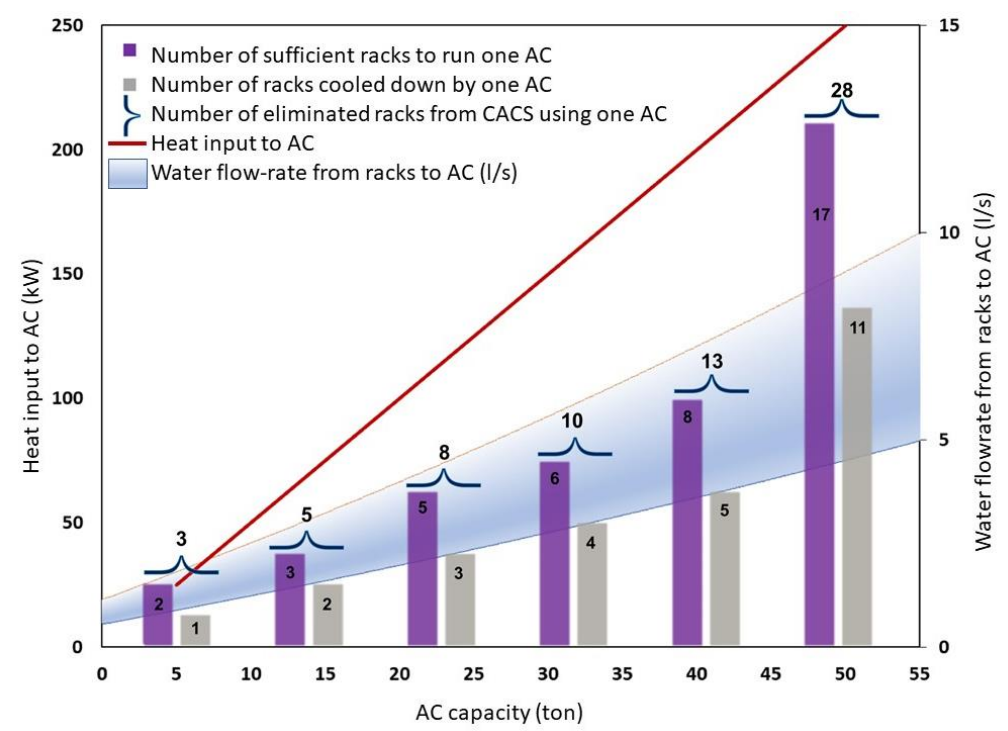

Figure 2. Heat dissipation by server racks and cooling process by AC chillers. 


\section{Results and Discussion}

\subsection{Energy Performance}

An energy analysis is imperative to make a decision for the selection of the best design. Therefore, Tables 1 and 2 present a detailed energy performance for both 4.5 and $13.5 \mathrm{MW}$ power consumed data centers, respectively. The cooling capacity and the performance of the AC systems depend on many parameters such as the heat source temperature, the flow rate, and the cooling water temperature. For example, for a 10 ton WFC-S10 Yazaki LiBr AC unit, the heat input and the pump power input are $15.2 \mathrm{~kW}_{\text {th }}$ and 0.18 $\mathrm{kW}_{\mathrm{e}}$, respectively [30,32]. Moreover, the cooling capacity is $9.8 \mathrm{~kW}_{\text {th }}[30,32]$. It should be mentioned that $\mathrm{kW}_{\mathrm{e}}$ represents the kilowatt electrical while $\mathrm{kW}_{\mathrm{th}}$ is a representative of kilowatt thermal. Accordingly, $\mathrm{COP}_{\mathrm{CC}}$ of 4 and $\mathrm{COP}_{\mathrm{AC}}$ of 0.63 for the $\mathrm{CC}$ system and $\mathrm{AC}$ system, respectively are assumed when the inlet hot water temperature from data center to $\mathrm{AC}$ is $70^{\circ} \mathrm{C}$. We also assume the total of $8760 \mathrm{~h}$ data center operates in one year. As a rule of thumb, for a conventional data center energy consumption of cooling system is equivalent to energy consumption of server racks. Electricity consumption for the CC system is equal to the number of racks multiply by power of each rack and total working hours in a year. Accordingly, electricity consumption by the proposed integrated system can be calculated through Equations (9) and (10). Table 1 presents electricity consumption for a $4.5 \mathrm{MW}$ and 13.5 MW data center comprising 300 and 900 server racks, respectively.

Table 1. Energy analysis for cooling a 4.5 MW and 13.5 MW data center comprising 300 and 900 racks with chillers of 575 ton and 1600 ton capacity.

\begin{tabular}{|c|c|c|c|}
\hline Power Consumption & Conventional Compression Chiller (CC) & Proposed Waste Heat Recovery System & $\begin{array}{l}\text { Energy Saving } \\
\text { (kWh/Year) }\end{array}$ \\
\hline \multirow{2}{*}{ 4.5 MW } & \multicolumn{2}{|l|}{ Cooling Electricity consumption (kWh/year) } & \multirow{2}{*}{$4,340,000$} \\
\hline & $\mathrm{W}_{\text {electricity-conventional }}=9,855,000$ & $\mathrm{~W}_{\text {electricity-hybrid }}=5,515,000$ & \\
\hline \multirow{2}{*}{ 13.5 MW } & Cooling Electricity consumption $(\mathrm{kWh} / \mathrm{y}$ & & \multirow{2}{*}{$13,025,000$} \\
\hline & $\mathrm{W}_{\text {electricity-conventional }}=29,565,000$ & $\mathrm{~W}_{\text {electricity-hybrid }}=16,540,000$ & \\
\hline
\end{tabular}

For the 4.5 MW data center, it is estimated that 13 racks can be covered with AC systems of 25 ton capacity. The direct dissipation occurs by means of the AC system generator for eight of the racks, while the remaining five use the evaporator of the AC system. As a consequence, total of 299 server racks can be eliminated from a cold-aisle containment system (CACS) load (13 managed by each chiller) using 23 chillers of 25 ton capacity. The application of CACS is to confine the cold aisle allowing the rest of the data room to become a large hot-air return plenum. As a result, a drastic reduction is observed in the number of server racks cooled by CACS. This change results in a significant reduction in the CACS load. An alternative design for data centers can be considered as number of racks in multiples of 13 without any further need to CACS for cooling purposes. Note that each 25-ton AC unit is capable of saving footprint area of 2 racks.

For the 13.5 MW data center, the results indicate that a 50-ton AC chiller is sufficient to cover 28 racks in the data room. Approximately $60 \%$ of the racks (i.e., 17 out of 28 ) directly disperse the heat into the generator of the AC system. While the remaining $40 \%$ use evaporator of the AC system for the heat removal. Thus, it is estimated that 32 chillers of 50 ton capacity enables removal of 896 server racks from the CACS load (i.e., 28 managed by each chiller). Similarly, a significant reduction of 900 to 4 in the number of racks cooled by CACS unit is observed. Similarly, it is possible to design an alternate configuration of racks in multiples of 28 which ultimately drops the any need to cooling by CACS. However, a detailed calculation can be performed based on specific operational needs of the data center. Each 50 ton AC unit is capable of saving footprint area of 3 racks. 
Table 2. Economic analysis for a 4.5 and $13.5 \mathrm{MW}$ data center comprising 300 and 900 server racks with chillers of 575 ton and 1600 ton capacity.

\begin{tabular}{|c|c|c|}
\hline Power Consumption & Conventional Compression Chiller (CC) & Proposed Waste Heat Recovery System \\
\hline \multirow{8}{*}{ 4.5 MW } & Electricity cost (\$/year) & \\
\hline & $9,855,000 \mathrm{kWh} \times 0.12(\$ / \mathrm{kWh})=\$ 1,182,600$ & $9,855,000 \mathrm{kWh} \times 0.12(\$ / \mathrm{kWh})=\$ 1,182,600$ \\
\hline & Cooling cost (\$/year) & \\
\hline & $\begin{array}{l}\$ 1,182,600 \\
\text { (typical value for energy usage of a data center which is } \\
\text { proportional to the ones from server racks) }\end{array}$ & $\$ 1,182,600 \times($ Equation $(10))=\$ 661,800$ \\
\hline & Total annual cost (\$/year) & \\
\hline & $\$ 2,365,200$ & $\$ 1,844,400$ \\
\hline & The prices of the chillers and cooling tower & \\
\hline & & $575 * \times \$ 2500=\$ 1,437,500$ \\
\hline \multirow{8}{*}{$13.5 \mathrm{MW}$} & Electricity cost (\$/year) & \\
\hline & $29,565,000 \mathrm{kWh} \times 0.12(\$ / \mathrm{kWh})=\$ 3,547,800$ & $29,565,000 \mathrm{kWh} \times 0.12(\$ / \mathrm{kWh})=\$ 3,547,800$ \\
\hline & Cooling cost (\$/year) & \\
\hline & $\begin{array}{l}\$ 3,547,800 \\
\text { (typical value for energy usage of a data center which is } \\
\text { proportional to the ones from server racks) }\end{array}$ & $\$ 3,547,800 \times($ Equation $(10))=\$ 1,984,800$ \\
\hline & Total annual cost (\$/year) & \\
\hline & $\$ 7,095,600$ & $\$ 5,532,600$ \\
\hline & The prices of the chillers and cooling tower & \\
\hline & & $1600 * \times \$ 2500=\$ 4,000,000$ \\
\hline
\end{tabular}

\footnotetext{
* Capacity of chillers and cooling towers.
}

\subsection{Economic Performance}

An economic analysis is imperative to make a decision for the selection of the best design. Therefore, Table 2 presents a detailed economic analysis for both 4.5 and $13.5 \mathrm{MW}$ power consumed data centers, respectively. The total annual electricity cost for each scenario comprises (1) electricity cost to run the servers and (2) energy cost to operate the cooling infrastructure. Electricity consumption of the data center is calculated based on the average power per racks by the number of servers in each rack. Therefore, the electricity consumption and its associated costs for running the servers in each rack is equal for both scenarios. On the other hand, the electricity associated with the infrastructure equipment (i.e., cooling systems) is calculated for two different scenarios (i.e., the conventional system and the proposed hybrid system).

A rough payback period is calculated based on the given assumptions in Table 2. The rough payback analysis provides how long the obtained savings from the use of the new system will take to pay back for the initial capital cost of the introduced system. As the operating expense and maintenance cost of the AC system is not included in the calculations, it is not possible to have a precise number for the payback period. The simple payback period for the proposed CC-AC system is calculated through Equation (11).

$$
\text { Payback period (year) }=\frac{\text { Saving Cooling Cost }(\$ / \text { year })}{\text { Total costs of the AC and cooling tower }}
$$

Thus, the simple payback estimation of the employment of AC in a $4.5 \mathrm{MW}$ data center is estimated 2.76 years. The payback period for the 13.5 MW data center is, however, calculated between 2.56 years indicating scaling up the data center can enhance the profitability of the low-grade waste heat recovery system. 
The results indicate that an AC system with a range of 5 to 50 ton capacity can afford adequate coolth energy to keep one more rack in the safe temperature level by waste heat dissipation from 2 to 17 racks. It is also evident that the AC system provides a faster payback period for a larger scale data center.

\subsection{Environmental Performance}

As stated earlier, there is growing demand for computing capacity resulting in development of data centers with significant power loads and densities around the globe [33]. Furthermore, the new generation of Central Processing Units (CPUs) can dissipate a remarkable amount of power in excess of 400 watts across the surface area of a credit card [34]. Safe operation of data centers, including numerous pieces of electronic equipment, requires proper temperature management based on the thermal envelopes provided by standardization entities. Full thermo- hygrometric state of the data centers environment must be actively inspected to lessen the potential risk of waste heat discharge to the environment or condensate the moist air when humidity raises. Therefore, management of thermal pollution in data centers is of significant importance.

The principle objective of controlling environment in data centers is to meet the timevarying cooling demand. According to the American Society of Heating, Refrigerating and Air-Conditioning Engineers (ASHRAE) [35], economic considerations have been changing the controlled environmental conditions of the data centers. Cooling data centers can cost up to a quarter of total energy expenses. In its first thermal guidelines for data centers, ASHRAE recommended air temperature envelope for data centers was $20-25^{\circ} \mathrm{C}$ based on both reliability and uptime (primary concerns) and energy costs secondary (concerns). As a result, four classes of data center equipment; A1, A2, A3 and A4 (Table 3).

Table 3. Four classes of data centers according to ASHRAE.

\begin{tabular}{ccc}
\hline Class & Temperature Range $\left({ }^{\circ} \mathrm{C}\right)$ & Humidity Range (\%) \\
\hline A1 & $15-32$ & $20-80$ \\
\hline A2 & $10-35$ & $20-80$ \\
\hline A3 & $5-40$ & $8-85$ \\
\hline A4 & $5-45$ & $8-90$ \\
\hline
\end{tabular}

The majority of today's data centers falls into class A1 and A2, nonetheless, many of modern manufacturers have been commercializing equipment compatible with class A3 and A4 operation.

As shown in Table 1, the amount of energy saving from the proposed systems of 4.5 MW and 13.5 MW power consumed data centers are 4,340,000 kWh/year and $13,025,000 \mathrm{kWh} /$ year, respectively. Considering every kWh emits averagely $7.07 \times 10^{-4}$ metric tons $\mathrm{CO}_{2}$ [36], the proposed $\mathrm{AC}$ system is estimated to save $3068 \mathrm{t} \mathrm{CO}_{2}$ /year and $9208 \mathrm{t}$ $\mathrm{CO}_{2}$ /year. These amounts of $\mathrm{CO}_{2}$ are approximately equal to 9066 and 27,190 barrels of crude oil. Furthermore, it is estimate that this GHG emission reduction is equivalent to 358 ha and 1074 ha of additional forest to adsorb this $\mathrm{CO}_{2}$ from the atmosphere.

\section{Conclusions}

In the existing energy conversion systems for decentralized source of heat, the majority of primary energy is lost as waste heat. This could be an enormous source of energy particularly in high energy consumption enterprises such as data centers. The highest portion of the energy lost in the data centers are classified as a low-grade waste heat and basically is the most challenging part to be recovered, especially when the temperature of waste heat is below $100{ }^{\circ} \mathrm{C}$. Absorption chiller systems are known as a well-established technology to recover the low-grade waste heat. The advancement of IoT technologies and its interaction with big data and could computing are extensively increasing leading to significant development of data centers. Thus, this research investigated feasibility of 
heat recovery options and analyzed the techno-economic aspect of an absorption chiller system for the low-grade waste heat recovery from a data center. The results of this study necessitate consideration of both technical and economic aspects at the same time. The proposed hybrid system enables saving electricity for the value of $4.3 \mathrm{GWh} /$ year and 13.0 GWh/year leading to an annual reduction of 3068 and 9208 tons $\mathrm{CO}_{2}$ equivalent of greenhouse gas (GHG) emissions, respectively. Furthermore, the simple payback of 2.76 and 2.56 years, respectively, for the employment of proposed system in a $4.5 \mathrm{MW}$ and 13.5 MW data center is estimated. Moreover, the environmental analysis also shows that $\mathrm{AC}$ system is a promising option for waste heat recovery and save notable equivalent carbon emissions to the environment. It is concluded that enhancing the capacity of the AC system enables waste heat dissipation of higher number of racks while shorten the payback period. Future work could focus on the employment of higher-performance absorbers and generators for designing new absorption cycles.

Author Contributions: L.A.: Conceptualization, investigation, methodology, software, validation, writing - original draft, writing — review and editing. E.M.: conceptualization, validation, writingreview and editing. N.B.: conceptualization, validation, writing-review \& editing. S.A.G.-M.: supervision, writing-review and editing. All authors have read and agreed to the published version of the manuscript.

Funding: This research received no external funding.

Institutional Review Board Statement: Not applicable.

Informed Consent Statement: Not applicable.

Data Availability Statement: The data presented in this study are openly available at https: / / doi. org /10.3390/xxxxx.

Acknowledgments: The first author acknowledge the financial support provided by the Killam Trusts fund scholarships and Dalhousie University.

Conflicts of Interest: The authors declare no conflict of interest.

$\begin{array}{ll}\text { Abbreviations } \\ \text { CC } & \text { Conventional Compression Chiller } \\ \text { AC } & \text { Absorption Chiller } \\ \text { CACS } & \text { Cold-Aisle Containment System } \\ \text { IoT } & \text { Internet of Things } \\ \text { IT } & \text { Information Technology } \\ \text { ORC } & \text { Organic Rankine Cycle } \\ \text { EA } & \text { Enclosed Aisle } \\ \text { OA } & \text { Open Aisle } \\ \text { GHG } & \text { Greenhouse Gas }\end{array}$

\section{References}

1. Huang, P.; Copertaro, B.; Zhang, X.; Shen, J.; Löfgren, I.; Rönnelid, M.; Fahlen, J.; Andersson, D.; Svanfeldt, M. A review of data centers as prosumers in district energy systems: Renewable energy integration and waste heat reuse for district heating. Appl. Energy 2020, 258, 114109. [CrossRef]

2. Koomey, J. Growth in Data Center Electricity Use 2005 to 2010; Anal. Press: City, Country, 2011; pp. 1-24. Available online: https://alejandrobarros.com/wp-content/uploads/old/Growth_in_Data_Center_Electricity_use_2005_to_2010.pdf (accessed on 1 January 2020).

3. Dandres, T.; Moghaddam, R.F.; Nguyen, K.K.; Lemieux, Y.; Samson, R.; Cheriet, M. Consideration of marginal electricity in real-time minimization of distributed data centre emissions. J. Clean. Prod. 2017, 143, 116-124. [CrossRef]

4. Rong, H.; Zhang, H.; Xiao, S.; Li, C.; Hu, C. Optimizing energy consumption for data centers. Renew. Sustain. Energy Rev. 2016, 58, 674-691. [CrossRef]

5. Van Heddeghem, W.; Lambert, S.; Lannoo, B.; Colle, D.; Pickavet, M.; Demeester, P. Trends in worldwide ICT electricity consumption from 2007 to 2012. Comput. Commun. 2014, 50, 64-76. [CrossRef]

6. Huang, Q.; Shao, S.; Zhang, H.; Tian, C. Development and composition of a data center heat recovery system and evaluation of annual operation performance. Energy 2019, 189, 116200. [CrossRef] 
7. Ebrahimi, K.; Jones, G.F.; Fleischer, A.S. A review of data center cooling technology, operating conditions and the corresponding low-grade waste heat recovery opportunities. Renew. Sustain. Energy Rev. 2014, 31, 622-638. [CrossRef]

8. Samadiani, E.; Joshi, Y. Energy efficient thermal management of data centers via open multi-scale design: A review of research questions and approaches. J. Enhanc. Heat Transf. 2011, 18, 15-30. [CrossRef]

9. van de Bor, D.; Ferreira, C.I.; Kiss, A.A. Low grade waste heat recovery using heat pumps and power cycles. Energy 2015, 89, 864-873. [CrossRef]

10. Yang, S.; Wang, Y.; Gao, J.; Zhang, Z.; Liu, Z.; Olabi, A.G. Performance Analysis of a Novel Cascade Absorption Refrigeration for Low-Grade Waste Heat Recovery. ACS Sustain. Chem. Eng. 2018, 6, 8350-8363. [CrossRef]

11. Amiri, L.; Madadian, E.; Hassani, F.P. Energo- and exergo-technical assessment of ground-source heat pump systems for geothermal energy production from underground mines. Environ. Technol. 2018, 40, 3534-3546. [CrossRef]

12. Amiri, L.; De Brito, M.A.R.; Baidya, D.; Kuyuk, A.F.; Ghoreishi-Madiseh, S.A.; Sasmito, A.P.; Hassani, F.P. Numerical investigation of rock-pile based waste heat storage for remote communities in cold climates. Appl. Energy 2019, 252, 113475. [CrossRef]

13. Zimmermann, S.; Meijer, I.; Tiwari, M.K.; Paredes, S.; Michel, B.; Poulikakos, D. Aquasar: A hot water cooled data center with direct energy reuse. Energy 2012, 43, 237-245. [CrossRef]

14. Davies, G.; Maidment, G.; Tozer, R. Using data centres for combined heating and cooling: An investigation for London. Appl. Therm. Eng. 2016, 94, 296-304. [CrossRef]

15. Fang, H.; Xia, J.; Zhu, K.; Su, Y.; Jiang, Y. Industrial waste heat utilization for low temperature district heating. Energy Policy 2013, 62, 236-246. [CrossRef]

16. Wang, Z.; Ren, T.; Ma, L.; Zhang, J. Investigations of Ventilation Airflow Characteristics on a Longwall Face-A Computational Approach. Energies 2018, 11, 1564. [CrossRef]

17. Xie, M.; Wang, J.; Liu, J. Evaluation metrics of thermal management in data centers based on exergy analysis. Appl. Therm. Eng. 2019, 147, 1083-1095. [CrossRef]

18. Wang, Y.; Sun, X.; Dai, Y.; Wu, G.; Cao, Y.; Huang, D. Numerical investigation of drag reduction by heat-enhanced cavitation. Appl. Therm. Eng. 2015, 75, 193-202. [CrossRef]

19. Gupta, R.; Moazamigoodarzi, H.; MirhoseiniNejad, S.; Down, D.G.; Puri, I.K. Workload management for air-cooled data centers: An energy and exergy based approach. Energy 2020, 209, 118485. [CrossRef]

20. Ahmadi, V.E.; Erden, H.S. A parametric CFD study of computer room air handling bypass in air-cooled data centers. Appl. Therm. Eng. 2020, 166, 114685. [CrossRef]

21. Nadjahi, C.; Louahlia, H.; Lemasson, S. A review of thermal management and innovative cooling strategies for data center. Sustain. Comput. Inform. Syst. 2018, 19, 14-28. [CrossRef]

22. Schmidt, R.; Cruz, E. Cluster of High-Powered Racks Within a Raised-Floor Computer Data Center: Effect of Perforated Tile Flow Distribution on Rack Inlet Air Temperatures. J. Electron. Packag. 2004, 126, 510-518. [CrossRef]

23. Erden, H.S.; Koz, M.; Yildirim, M.T.; Khalifa, H.E. Experimental Demonstration and Flow Network Model Verification of Induced CRAH Bypass for Cooling Optimization of Enclosed-Aisle Data Centers. IEEE Trans. Compon. Packag. Manuf. Technol. 2017, 7, 1795-1803. [CrossRef]

24. Demetriou, D.W.; Khalifa, H.E. Optimization of Enclosed Aisle Data Centers Using Bypass Recirculation. J. Electron. Packag. 2012, 134, 020904. [CrossRef]

25. Yu, J.; Jiang, Y.; Yan, Y. A simulation study on heat recovery of data center: A case study in Harbin, China. Renew. Energy 2019, 130, 154-173. [CrossRef]

26. Ebrahimi, K.; Jones, G.F.; Fleischer, A.S. The viability of ultra low temperature waste heat recovery using organic Rankine cycle in dual loop data center applications. Appl. Therm. Eng. 2017, 126, 393-406. [CrossRef]

27. Araya, S.; Jones, G.F.; Fleischer, A.S. Organic Rankine Cycle as a Waste Heat Recovery System for Data Centers: Design and Construction of a Prototype. In Proceedings of the 2018 17th IEEE Intersociety Conference on Thermal and Thermomechanical Phenomena in Electronic Systems (ITherm); Institute of Electrical and Electronics Engineers (IEEE), San Diego, CA, USA, 29 May-1 June 2018; pp. 850-858.

28. Araya, S.; Wemhoff, A.P.; Jones, G.F.; Fleischer, A.S. Study of a Lab-Scale Organic Rankine Cycle for the Ultra-Low-Temperature Waste Heat Recovery Associated WITH Data Centers. J. Electron. Packag. 2020, 143. [CrossRef]

29. Thermax. Hot Water Driven Vapor Absorption Machine. Instrumentation. Available online: https://www.trane.com/content/ dam/Trane/Commercial/global/products-systems/equipment/chillers/absorption-liquid/hotwater_drivenabsorptionchillers. pdf (accessed on 1 January 2020).

30. VAMTEC I YAZAKI Hot Water Absorption Chiller. Available online: https://www.vamtec.com/absorption-chiller/ (accessed on 1 January 2020).

31. Marcinichen, J.B.; Olivier, J.A.; Thome, J.R. On-chip two-phase cooling of datacenters: Cooling system and energy recovery evaluation. Appl. Therm. Eng. 2012, 41,36-51. [CrossRef]

32. Haywood, A.; Sherbeck, J.; Phelan, P.; Varsamopoulos, G.; Gupta, S.K. Thermodynamic feasibility of harvesting data center waste heat to drive an absorption chiller. Energy Convers. Manag. 2012, 58, 26-34. [CrossRef]

33. Dreibholz, T.; Becke, M.; Adhari, H. Report to Congress on Server and Data Center Energy Efficiency Public Law 109-431; Tdr.Wiwi.UniDue.De 109; 2007; p. 431. Available online: https:/ /www.osti.gov/biblio/929723 (accessed on 1 January 2020).

34. Corporation, I. Product Specifications, Processors; 2019. 
35. ASHRAE. Data Center Power Equipment Thermal Guidelines and Best Practices; Standard, 2016; pp. 1-60.

36. EPA. AVERT, U.S. National Weighted Average $\mathrm{CO}_{2}$ Marginal Emission Rate, Year 2017 Data; U.S. Environmental Protection Agency, 2018. 